\title{
Radiocarbon
}

1979

\section{THE QUATERNARY ISOTOPE LABORATORY THERMAL DIFFUSION ENRICHMENT SYSTEM : DESCRIPTION AND PERFORMANCE}

\author{
PIETER M GROOTES and MINZE STUIVER
}

Quaternary Isotope Laboratory, University of Washington, Seattle, Washington 98195

\begin{abstract}
The thermal diffusion enrichment system of the Quaternary Isotope Laboratory consists of 23 hot wire columns of $3 \mathrm{~m}$ effective length combined to 2 separate systems of 3 and 3 separate systems of 4 columns at the top, each system in series

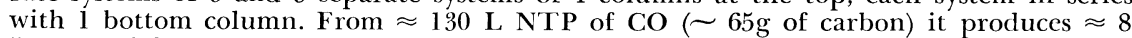
$\mathrm{L}$ NTP of $\mathrm{CO}\left(\sim 4 \mathrm{~g}\right.$ of carbon) enriched in ${ }^{12} \mathrm{C}^{18} \mathrm{O}$ by a factor 6 to 7 and in ${ }^{14} \mathrm{C}^{16} \mathrm{O}$ by a factor 7 to 8 in about 5 weeks. For ${ }^{12} \mathrm{C}^{18} \mathrm{O}$ the system has a theoretical equilibrium separation factor of about 250 and a theoretical equilibrium enrichment of about 15 . For ${ }^{14} \mathrm{C}^{16} \mathrm{O}$ these values are 1300 and 16 , respectively. The dependence of thermal diffusion transport on gas exchange between top and bottom section and between columns and reservoirs and on wire temperature is given. Forced gas exchange and a higher wire temperature gave a more rapidly increasing enrichment without substantially increasing its final value of 6 to 7 for ${ }^{12} \mathrm{C}^{18} \mathrm{O}$. A comparison with the Groningen enrichment system shows that the two systems behave very similarly and that not the system geometry but individual column parameters and the ratio total sample mass/enriched sample mass are the dominant factors determining the enrichment.
\end{abstract}

\section{INTRODUCTION}

In the Quaternary Isotope Laboratory at the University of Washington the radiocarbon dating range for a 4-day counting period has been increased to 60,000 years by the use of carefully constructed and shielded large counters placed in an underground measuring chamber (Stuiver, Robinson, and Yang, 1976). Another approach to an extended age range has been the construction of an enrichment system to increase by a known factor the ${ }^{14} \mathrm{C}$ activity of very old samples. This has pushed the dating range back to 75,000 years (Stuiver, Heusser, and Yang, 1978). In the apparatus, a large amount of sample in the form of CO gas $(\approx 130 \mathrm{~L} \mathrm{NTP}$ $\sim 65 \mathrm{~g}$ of $\mathrm{C}$ ) is subjected to thermal diffusion (TD) isotope separation. A smaller quantity of gas $(\approx 8 \mathrm{~L}$ NTP $\sim 4 \mathrm{~g}$ of $\mathrm{C})$ enriched in the heavy isotopes is obtained.

The use of $\mathrm{CO}$ for the enrichment of ${ }^{14} \mathrm{C}$ and the relation between the simultaneous enrichments of the isobaric molecules ${ }^{14} \mathrm{C}^{16} \mathrm{O}$ and ${ }^{12} \mathrm{C}^{18} \mathrm{O}$, important to determine the ${ }^{14} \mathrm{C}$ enrichment, were first studied by de Vries (1956). The study resulted in the construction, in Amsterdam, of a thermal diffusion enrichment set-up used to enrich ${ }^{14} \mathrm{C}$ samples for the Groningen Radiocarbon Dating Laboratory. This extended the range of this laboratory to 70,000 years (Haring, de Vries, and de Vries, 1958; Vogel and Zagwijn, 1967; Vogel and Waterbolk, 1972). Contamination resulted in a temporary halt of the enrichment activities until, in 1970, the Amsterdam enrichment system was relocated to Groningen. After the earlier 
contamination problems had been solved, a series of dates up to 73,000 years BP were obtained (Grootes et al, 1975; Grootes, 1977; 1978).

The use of thermal diffusion enrichment to extend the range of radiocarbon dating has also been studied in other laboratories. Concentric tube columns for the enrichment of ${ }^{14} \mathrm{C}$ in methane were constructed and studied by Dickel and coworkers in Munich (Malota, 1962; Kretner, 1973; Kretner and Dickel, 1975), by Erlenkeuser (1971a, b, 1976) in Kiel, and by Felber and Pak in Vienna (Pak, 1970; Felber and Pak, 1972). None of these systems appears to be operational for radiocarbon dating yet. The present day radiocarbon dating range is, therefore, the 75,000 years obtained at the Quaternary Isotope Laboratory and in Groningen.

The newly developed technique of direct detection of ${ }^{14} \mathrm{C}$ using an accelerator as a very sensitive mass spectrometer (Muller, 1977; Muller, Stephenson and Mast, 1978; Bennet et al, 1977; 1978; Nelson, Korteling, and Scott, 1977) may give a similar range when the problems of contamination and machine and source instability have been vanquished. The main advantage of this new method is that it enables age determinations on very small samples ( $c f$ Stuiver, 1978).

The construction of the present University of Washington (UW) system began at Yale in the late sixties. $\mathrm{CO}$ was chosen as the enrichment medium because (i) it is light (ie, the relative mass difference between ${ }^{14} \mathrm{C}^{16} \mathrm{O}$ and ${ }^{12} \mathrm{C}^{16} \mathrm{O}$ is large); (ii) its intermolecular interaction has a short range, which is favorable for TD separation; (iii) it has a fairly good thermal stability; (iv) it is very easy to make by passing $\mathrm{CO}_{2}$, the first step in the preparation of any ${ }^{14} \mathrm{C}$ sample, over hot zinc; (v) it offers the possibility to determine the ${ }^{14} \mathrm{C}$ enrichment by measuring the simultaneous enrichment of molecules of mass 30 (mainly ${ }^{12} \mathrm{C}^{18} \mathrm{O}$ ) mass spectrometrically. The alternative, $\mathrm{CH}_{4}$, was less attractive because the advantage of its smaller mass is offset by a longer interaction range and less thermal stability, while its production, although also a standard procedure in many laboratories (Agrawal, Gupta, and Kusumgar, 1971; Buddemeier et al, 1970), is somewhat more complicated for the large samples used. $\mathrm{CH}_{4}$ also does not readily offer a check on the enrichment. The fact that any tritium contamination incorporated in the methane will undergo an enrichment similar to that of ${ }^{14} \mathrm{C}$ is an additional complication for the dating of samples in the 50,000 to 75,000 year range.

In the UW system, the same basic columns were used as in the original de Vries system in Amsterdam, but the geometric configuration is different. In this paper, we describe the enrichment set-up and compare its performance with that of the Amsterdam-Groningen thermal diffusion system and with theory.

\section{APPARATUS}

Before an enrichment sample can be counted, it must undergo the following conversions: (i) combustion to $\mathrm{CO}_{2}$; (ii) reduction to $\mathrm{CO}$; (iii) enrichment; (iv) oxidation to $\mathrm{CO}_{2}$. We will first discuss these conversions.

Combustion of the pretreated sample takes place in a system that is only used for old samples. It is similar to the system for routine combus- 
tion of ${ }^{14} \mathrm{C}$ samples (de Vries and Barendsen, 1953), but its dimensions have been changed to produce large quantities of $\mathrm{CO}_{2}$. Typically, the UW system produces about $100 \mathrm{~L}$ NTP of $\mathrm{CO}_{2}$ in 5 hours.

In the reduction system, the $\mathrm{CO}_{2}$ sample is reduced to $\mathrm{CO}$ by passing through a zinc-asbestos mixture (10 to 1 by weight) at about $400^{\circ} \mathrm{C}$. Basic aspects of system and procedure are similar to that described by Grootes et al (1975). A large batch of zinc-asbestos is used which can reduce between 5 and 10 samples before replacement is needed. Typically, about $10 \mathrm{~L}$ NTP of $\mathrm{CO}$ is produced in 1 hour at a pressure difference over the zinc-asbestos of about 350 torr. The $\mathrm{CO}$ is condensed with liquid nitrogen (vapor pressure $\approx 470$ torr at liquid nitrogen temperature) to keep the pressure in the system low. When the reduction has been completed, the $\mathrm{CO}$ is fed into the thermal diffusion system through a cold trap to catch any $\mathrm{CO}_{2}$ that is still present.

The enrichment system consists of 23 single thermal diffusion columns; 18 columns in parallel in a top section are combined in 2 sets of 3 and 3 sets of 4 columns that are each in series with a single column in the bottom section (fig 1). Each column is of the Clusius-Dickel type and consists of a pyrex glass tube with an inner diameter of $1.0 \mathrm{~cm}$ (top) or $0.9 \mathrm{~cm}$ (bottom section). A $0.3 \mathrm{~mm}$ diameter Platinum-Iridium $(80 \%-20 \%)$ wire is suspended in the center. The effective length of the wire and column is $3.0 \mathrm{~m}$. The wall of the pyrex tube is cooled on the outside by water flowing up between the wall and a second concentric pyrex tube of $3 \mathrm{~cm}$ diameter. The column construction is similar to that published by Grootes et al (1975), except for the lack of spacers, which facilitated construction.

The top columns are interconnected at the bottom; they must be separate at the top to prevent parasitic convection caused by small temperature differences between the columns. Therefore each top column has its own $5 \mathrm{~L}$ storage reservoir. The gas from these reservoirs is circulated over the top of the columns by convection. The connection between topand bottom columns forms a parasitic volume of $\approx 74 \mathrm{~cm}^{3}(3$ column system) and $\approx 93 \mathrm{~cm}^{3}(4)$. Each of the bottom columns is connected to an enrichment reservoir of $1.2 \mathrm{~L}$ (the sets of 3 ) or $1.6 \mathrm{~L}$ (the sets of 4 columns). The gas in these reservoirs is combined with that of the bottom columns for the enriched sample. The enrichment is made at a pressure of about 850 torr. Power consumption is about $1 \mathrm{~kW}(67 \mathrm{~V}, 15 \mathrm{~A})$ and $0.8 \mathrm{~kW}$ $(67 \mathrm{~V}, 12 \mathrm{~A})$ for the 4 and the 3 column systems, respectively, $(\sim 0.67$ $\mathrm{W} / \mathrm{cm}$ wire), resulting in a wire temperature of about $960 \mathrm{~K}$. The storage and enrichment reservoir and the parasitic volume are at ambient temperature which, near the system, is $\approx 300 \mathrm{~K}$. The cold wall temperature is estimated to be in the range of $25-45^{\circ} \mathrm{C}$, typically $308 \mathrm{~K}$. It varies with the flow rate of the cooling water $(\approx 6 \mathrm{~L} / \mathrm{min}, i e, 0.26 \mathrm{~L} / \mathrm{min} /$ column$)$ and with the seasonal fluctuations of the temperature of the water entering the columns (range $10-18^{\circ} \mathrm{C}$ ). Gas properties used in TD calculations are taken at the cold wall temperature of $308 \mathrm{~K}$. The average temperature of the gas in the columns is $416 \mathrm{~K}$. 


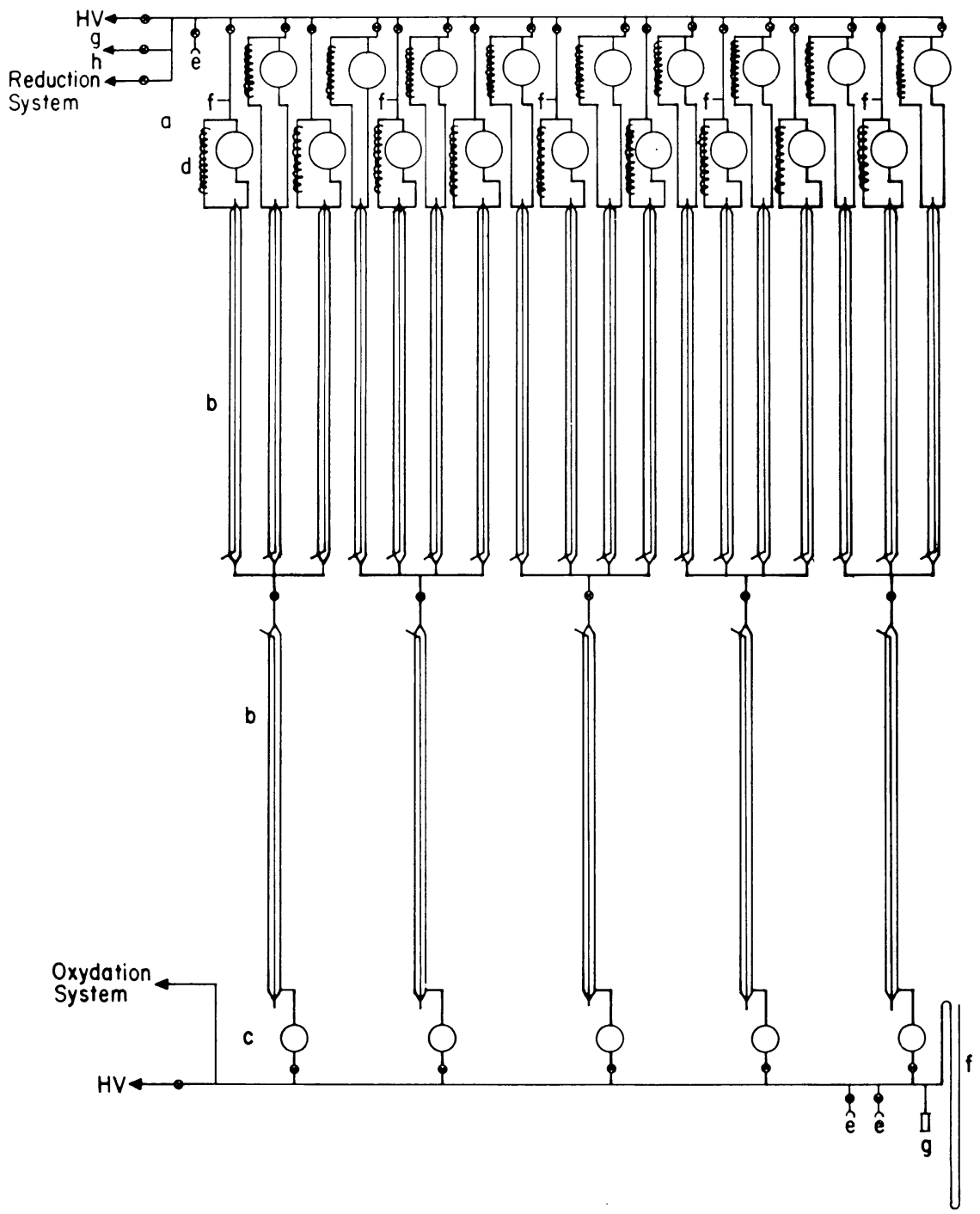

Fig. 1. Thermal diffusion enrichment system. a-storage volume $V_{-}$, b-thermal diffusion columns, $\mathrm{c}$-enriched sample volume $\mathrm{V}_{+}$, d-thermal circulation, e-sampling point, $\mathrm{f}$-mercury manometer, $\mathrm{g}$-thermocouple gauge, $\mathrm{h}$-Penning gauge, HV-high vacuum pump. 
In the oxidation system (fig 2) the enriched CO from the enrichment reservoirs plus bottom columns is converted back to $\mathrm{CO}_{2}$. The $\mathrm{CO}$ is first adsorbed on silica gel at liquid nitrogen temperature and then expanded through a $\mathrm{CuO}$ furnace at $450^{\circ} \mathrm{C}$ into a $10 \mathrm{~L}$ storage bulb. The gas mixture then circulates through the $\mathrm{CuO}$ by convection till the oxidation is complete. After about a week, the $\mathrm{CO}_{2}$ is condensed with liquid $\mathrm{N}_{2}$, expanding residual $\mathrm{CO}$ from the silica into the system, and the silica is closed off from the system. The oxidation is then resumed until completion, usually after 2 to 3 weeks. Virtually no non-condensable gas remains. Oxidation must be complete to ensure that any isotope fractionation taking place during the process does not influence the carbon isotopic composition of the sample. The oxygen isotopic composition will change because of exchange with the $\mathrm{CuO}$. The enriched $\mathrm{CO}_{2}$ sample is either cleaned further by circulation through a $\mathrm{Cu}$ furnace or transferred to a storage flask to wait for the radon decay (from the silica) and measurement. Before each oxidation, the $\mathrm{CuO}$ furnace is regenerated by heating at $\approx 450^{\circ} \mathrm{C}$ in oxygen. Then furnace and silica are thoroughly degassed.

Measurement: A Nuclide 6-60 RMS mass spectrometer operated in the single collector mode was used to measure the stable isotopic com-

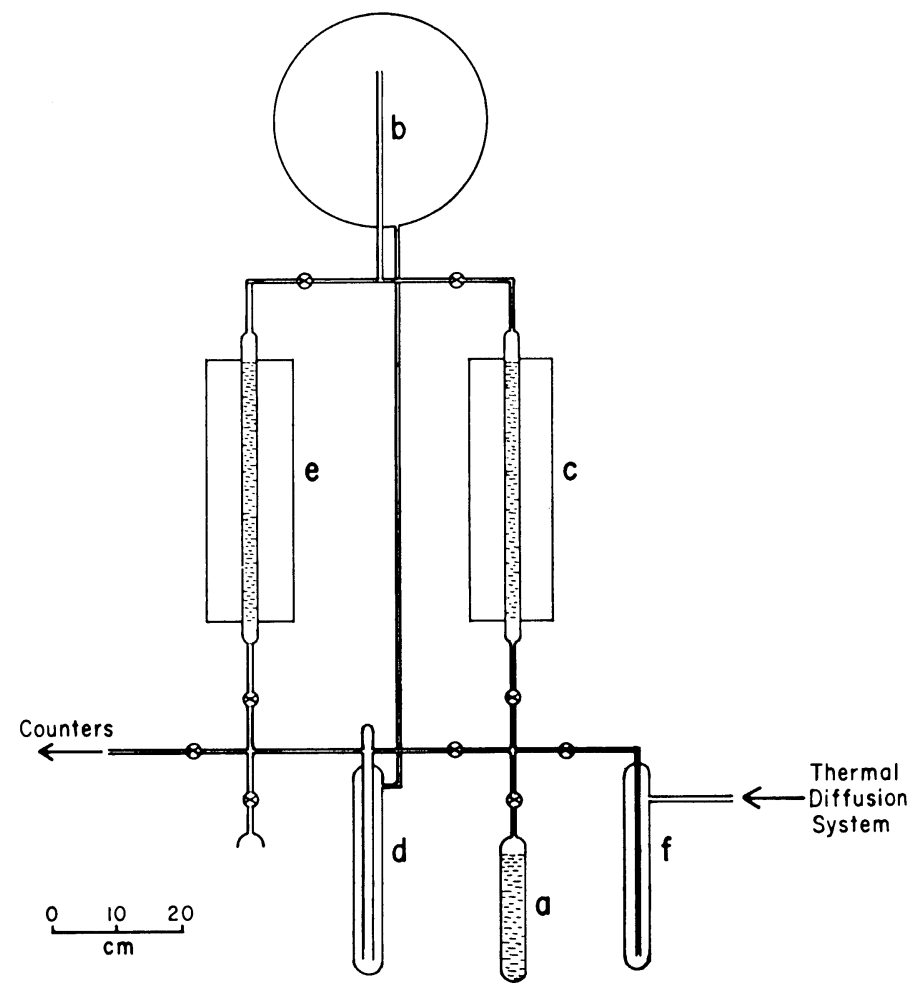

Fig. 2. Oxidation system. a-silica adsorber, b-10 L storage bulb, c-CuO furnace at $450^{\circ} \mathrm{C}, \mathrm{d}-\mathrm{CO}_{2}$ trap, e- $\mathrm{Cu}$ furnace at $450^{\circ} \mathrm{C}$, f-trap for $\mathrm{CO}_{2}$ in enriched $\mathrm{CO}$ sample. 
position (mass 28: ${ }^{12} \mathrm{C}^{16} \mathrm{O}$; mass 29: mainly ${ }^{13} \mathrm{C}^{16} \mathrm{O}$, some ${ }^{12} \mathrm{C}^{17} \mathrm{O}$; mass 30 : mainly ${ }^{12} \mathrm{C}^{18} \mathrm{O}$, some $\left.{ }^{13} \mathrm{C}^{17} \mathrm{O},{ }^{14} \mathrm{C}^{16} \mathrm{O}\right)$ of the sample. The small amount of gas needed for a mass spectrometric measurement makes it possible to sample the gas during the enrichment without seriously disturbing the system.

The ${ }^{14} \mathrm{C}$ activities were measured in a $2.3 \mathrm{~L}$ proportional $\mathrm{CO}_{2}$ counter (Stuiver, Robinson, and Yang, 1976).

\section{DISCUSSION}

The first question to be asked for a new enrichment system is, what and how fast can enrichment be obtained? Secondly, how does the system performance compare with other systems and with theory? The theory is important because it may indicate what improvements are possible in final enrichment or in the rate of enrichment. Theoretical detail is avoided in this paper, the specific calculations of which the results are used here will be published elsewhere. Discussed in the following sections are (a) the working and design of a single column and that of the complete system,

TABLE 1

\section{List of symbols}

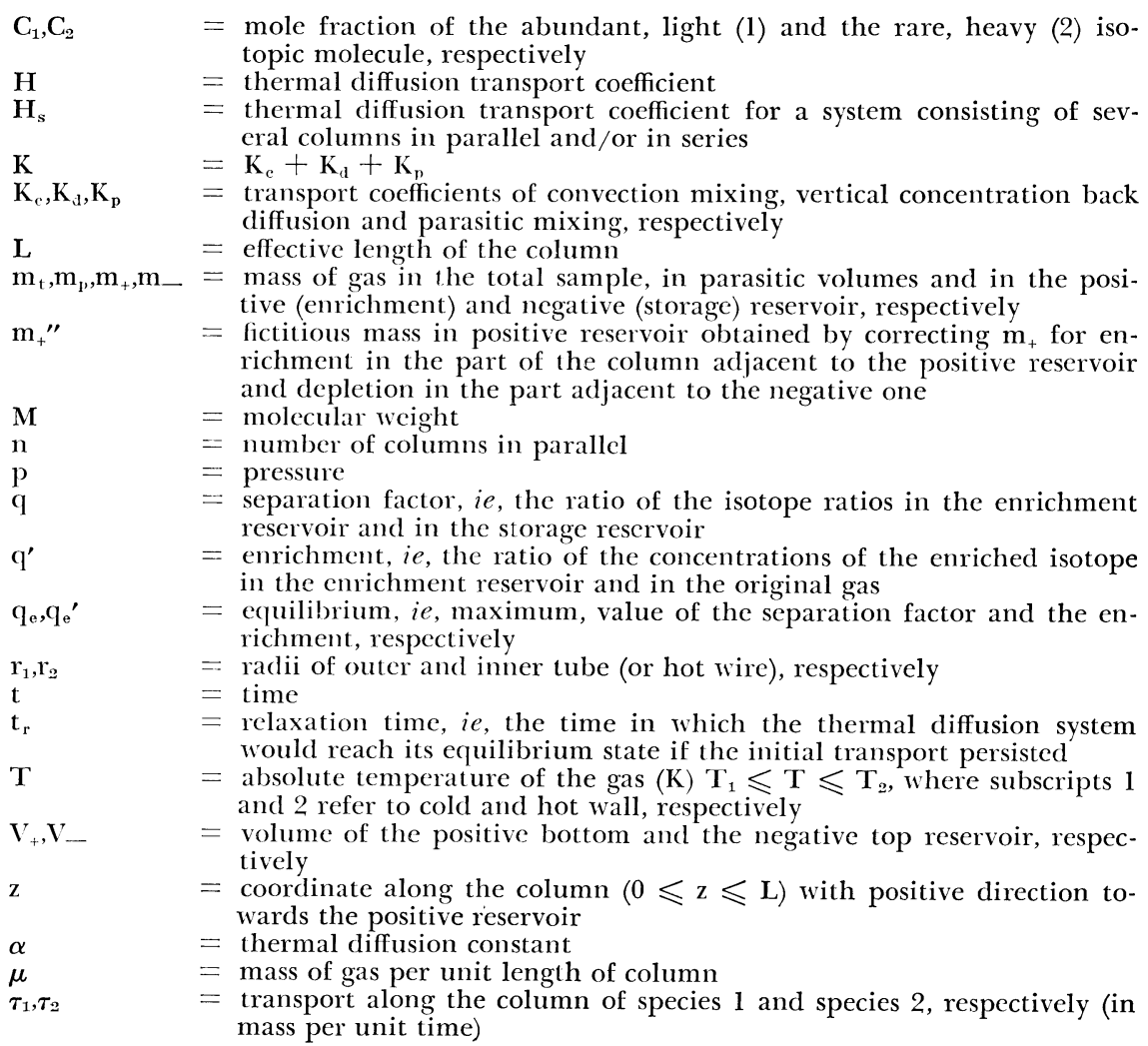


and (b) the performance of the enrichment system in terms of the initial transport and the following transient phase.

\section{Single column}

Thermal diffusion (TD) columns have been discussed by Jones and Furry (1946) and by Vasaru et al (1969). In this paper, the notation of Jones and Furry will be used mostly. A list of symbols and definitions is given in table 1 .

The TD column consists of a vertical tube which is cooled on the outside with a heated wire along its axis. In a horizontal cross section, the temperature gradient effects a small isotope separation in which, generally, the heavy isotopic molecules concentrate near the cold wall and the light ones near the hot wire. Convection currents, going down at the cold wall and up in the warm center part of the column, then result in a net transport of the heavy isotopes down the column and of the light isotopes to the top. As a result, a concentration gradient is built up along the tube.

The net transport of isotopes through the column is determined by 4 processes (fig 3):

(i) the TD process, which builds up a horizontal concentration gradient;

(ii) a horizontal back diffusion (HBD) due to this concentration gradient;

(iii) a convection current (CC), transporting the isotopically heavy gas downwards along the cold wall and the light gas upwards along the wire;

(iv) a vertical back diffusion (VBD) due to the vertical concentration gradient.

The convection current (CC) provides the net transport of isotopic molecules. However, when a vertical concentration gradient has been established, the current also replaces, in a horizontal cross section, the gas near the wire by isotopically heavier gas from below and near the cold wall by isotopically lighter gas from above. This reduces the concentration difference between the hot and the cold gas flow.

The net mass transport $\tau$ of a certain, rare isotope in a TD column is given by (Vasaru et al, 1969)

$$
\tau=\mathrm{HC}-\left(\mathrm{K}_{\mathrm{c}}+\mathrm{K}_{\mathrm{d}}\right) \partial \mathrm{C} / \partial \mathrm{z}
$$

where $\mathrm{H}, \mathbf{K}_{\mathrm{c}}$ and $\mathbf{K}_{\mathrm{t}}$ are system parameters called transport coefficients and $\mathrm{C}$ is the concentration of the isotope considered $(\mathrm{C}<<1)$. It is the difference between the thermal diffusion transport $\mathrm{HC}(\mathrm{H}$ proportional to $\mathrm{p}^{2}$ and $\left.\mathrm{r}_{1}{ }^{4}\right)$ and the convection mixing $\mathrm{K}_{\mathrm{c}} \partial \mathrm{C} / \partial \mathrm{z}\left(\mathrm{K}_{\mathrm{c}}\right.$ proportional to $\mathrm{p}^{4}$ and $\left.\mathrm{r}_{1}{ }^{8}\right)$ and diffusion mixing $\mathrm{K}_{\mathrm{a}} \partial \mathrm{C} / \partial \mathrm{z}\left(\mathrm{K}_{\mathrm{d}}\right.$ proportional to $\left.\mathrm{r}_{1}{ }^{2}\right)$. Here, $\mathrm{p}$ is the gas pressure in the column and $r_{1}$ is the radius of the hot wire column. Thus, a high thermal diffusion transport may be obtained in a large diameter tube at high pressure. This results only in a large net mass transport in the initial phase when concentration gradients are small and, consequently, diffusion and convection mixing are negligible. In the fol- 


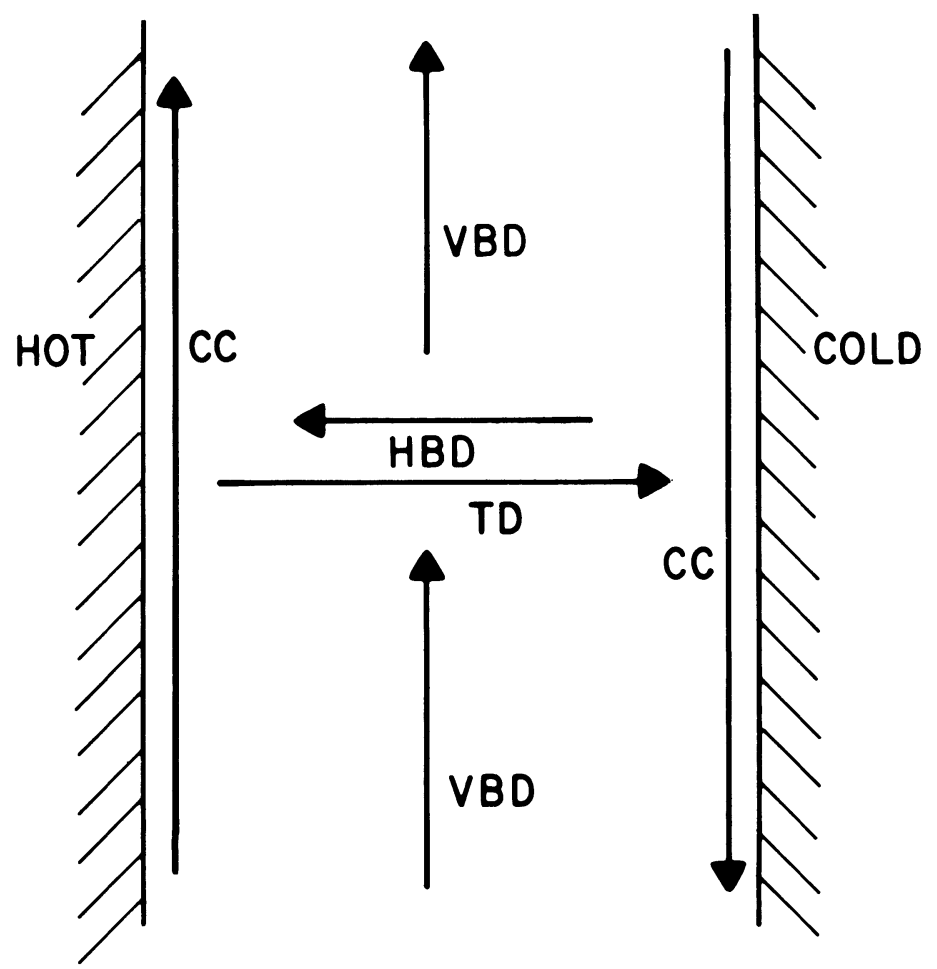

Fig. 3. Processes determining the net transport of isotopes in a thermal diffusion column; we consider the transport of the heavy isotopic species. TD-thermal diffusion isotope separation, HBD-horizontal back diffusion, CC-convection current, VBDvertical back diffusion.

lowing, transient phase net mass transport gradually decreases to zero as a concentration gradient along the column is built up. The decrease is determined by the approach of the concentration distribution to its equilibrium state where TD transport is balanced by convection mixing and concentration back diffusion. To describe the isotope separation, we define the separation factor $\mathrm{q}$ ( $\equiv$ isotope ratio on the enrichment side/ isotope ratio on the depletion side of the column) and the enrichment $\mathrm{q}^{\prime}$ (三the concentration of the (heavy) isotope considered in a certain volume divided by the original concentration of this isotope in the gas).

To obtain a net mass transport that persists in the transient phase until the desired enrichment in the enrichment reservoir has been obtained, we must make the maximum (= equilibrium) separation factor $\mathrm{q}_{\mathrm{e}}$ much larger than the $\mathrm{q}$ at which enrichment will be stopped. With $\tau$ $=0$ in equation $(1)$ we derive:

$$
\mathrm{q}_{\mathrm{e}}=\exp \left(\mathrm{HL} /\left(\mathrm{K}_{\mathrm{c}}+\mathrm{K}_{\mathrm{d}}\right)\right),
$$

where $\mathrm{L}$ is the effective length of the column. 
Because of the different functional dependences of $\mathrm{H}, \mathrm{K}_{\mathrm{c}}$ and $\mathrm{K}_{\mathrm{d}}$ on column radius $r_{1}$ and pressure $p$ a maximum of $q_{e}(p)$ is obtained if $K_{d}=$ $\mathrm{K}_{\mathrm{c}}$ and of $\mathrm{q}_{\mathrm{e}}\left(\mathrm{r}_{1}\right)$ if $\mathrm{K}_{\mathrm{d}}=2 \mathrm{~K}_{\mathrm{c}}$. A practical system will result from a compromise between a high initial net mass transport (large $\mathrm{H}$, but also $\mathrm{K}_{\mathrm{c}}$ $>>\mathrm{K}_{\mathrm{d}}$ ) and a maximum separation factor. Enrichment columns 0.9 to $1.0 \mathrm{~cm}$ in diameter filled with 800 to 900 torr of CO, having a cold wall temperature of about $300 \mathrm{~K}$ and a $0.3 \mathrm{~mm}$ diameter wire at about $950 \mathrm{~K}$ are such a practical compromise $\left(\mathrm{K}_{\mathrm{c}}\right.$ is $\mathbf{1}$ to $2 \mathrm{~K}_{\mathrm{d}}$ ) ( $c f$ Grootes, 1977).

Figure 4 shows a theoretical calculation of $\mathrm{q}_{\mathrm{e}}$ for ${ }^{12} \mathrm{C}^{18} \mathrm{O}$ as a function of pressure for different hot wire temperatures $T_{2}$ for a column of $1.0 \mathrm{~cm}$ diameter (top section). At low pressures diffusion mixing (independent of $p$ ) dominates over convection mixing and $\mathrm{q}_{\mathrm{e}}$ increases with pressure. For high pressures, however, the convection is dominant and, consequently, there $\mathrm{q}_{\mathrm{e}}$ decreases with increasing pressure.

\section{The enrichment system}

Both enrichment, and enrichment time, depend not only on the columns used, but also on the size of the reservoirs and on the connections between the columns and between columns and reservoirs.

The separation factor of a system of 2 or more columns in series is simply the product of the separation factors of the individual columns. The enrichment is determined mainly by the relative size of the different

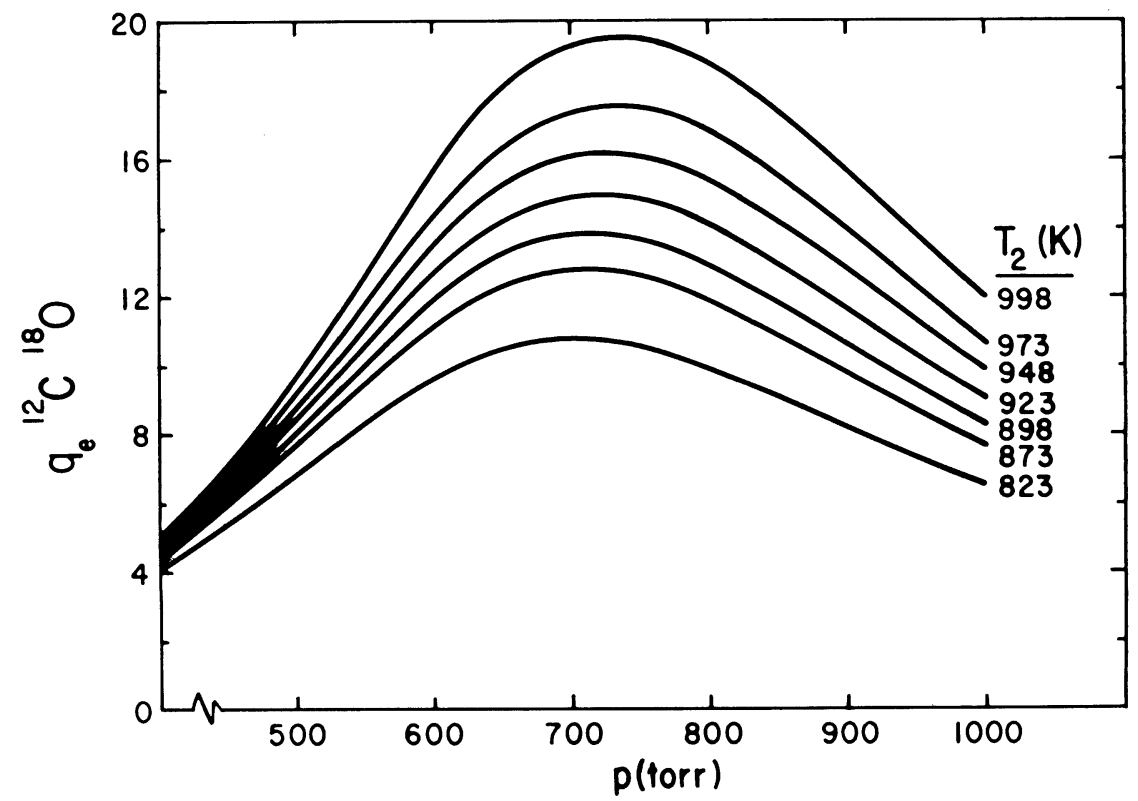

Fig. 4. Theoretical separation factor $\mathrm{q}_{\mathrm{e}}$ for ${ }^{12} \mathrm{C}^{18} \mathrm{O}$ of a single top column $\left(\mathrm{r}_{1}=\right.$ $0.5 \mathrm{~cm})$ as a function of pressure and wire temperature at a cold wall temperature $T_{1}$ $=300 \mathrm{~K}$. 
parts of the enrichment system over which the finite amount of the heavy isotopic species present in the total sample of mass $\mathrm{m}_{\mathrm{t}}$ is distributed, provided the equilibrium separation factor $\mathrm{q}_{\mathrm{e}}>>\mathrm{m}_{\mathrm{t}} / \mathrm{m}_{+}, e g, \mathrm{q}_{\mathrm{e}}>10$ $\mathrm{m}_{\mathrm{t}} / \mathrm{m}_{+}$, where $\mathrm{m}_{+}$is the mass of the gas in the enrichment volume $\mathrm{V}_{+}$. This means that although $\mathrm{q}_{\mathrm{e}}$ of a system may be quite high $(>1000)$ the maximum enrichment may still be small if $\mathrm{m}_{\mathrm{t}} / \mathrm{m}_{+}$is small. Because the initial net mass transport of an enrichment system is determined by the transport properties of the individual columns, and their combination, it is independent of the mass ratio $\mathrm{m}_{\mathrm{t}} / \mathrm{m}_{+}$. If we compare the enrichment in systems having largely different values of $\mathrm{m}_{\mathrm{t}}$ and the same $\mathrm{m}_{+}$, this means that initially both systems will give the same enrichment as a function of time. When enrichment in the small $m_{t}$ system approaches $q_{e}^{\prime}$, however, the enrichment in the large $\mathrm{m}_{\mathrm{t}}$ system will continue to increase till it also approaches its much larger equilibrium value after a proportionally longer time. To determine the enrichment of a system we thus have to consider it in detail.

\section{System geometry}

Figure 5 shows an enrichment system of $\mathbf{n}$ parallel columns with $\mathrm{r}_{1}=$ $0.50 \mathrm{~cm}$, each with its own storage reservoir, in series with a single column with $r_{1}=0.45 \mathrm{~cm}$. The TD transport of $\mathrm{n}$ parallel columns is $\mathrm{nHC}$. This means that if concentration $\mathrm{C}$ increases along the columns the number of columns can be decreased to give the same transport. Thus the use of two stages with the larger number of columns in parallel in the first is favorable. In the next section we discuss which value of $n$ gives the largest TD transport for a given number of TD columns, $i e$, a given input in construction and operating costs.

The driving force of the isotope separation is the TD transport in the top and bottom section columns. Concentration gradients in the system reduce the net mass transport. In the first place, this is the inevitable, gradually increasing, concentration gradient caused by the enrichment in $\mathrm{V}_{+}$. Secondly, in three regions of the system, transport must take place by concentration diffusion. These are from $\mathrm{V}_{-}$(ie, the convection flow of reservoir gas through the top of the column) to the beginning of TD transport ( $c f$ Rutherford and Kaminski, 1967), from the bottom of the top section to the top of the bottom column and from the bottom of this column to $\mathrm{V}_{+}$. Concentration gradients opposite to the ones in the columns exist in these regions. In the third place the concentration at the top of the bottom column has to be considerably higher (about $\mathrm{n}$ times, $\tau=$ $\mathrm{HC}-\mathrm{K} \partial \mathrm{C} / \partial \mathrm{z}$ ) than that at the top of the $\mathrm{n}$ top columns. The effect of these restraints on the concentration distribution in the system will be to reduce the net mass transport of the system even before any appreciable enrichment in $\mathrm{V}_{+}$has taken place.

If accumulation of heavy isotopes in and between the columns is small compared with the total transport, which it is, we may neglect it and assume a constant transport $\tau$ through the system, quasi-stationary assumption. Under this assumption the TD transport of a single column 
after a time $\mathrm{t}$ has been given by Felber and Pak (1974). Combination of their TD mass transport equation for the columns with expressions for the concentration diffusion mass transport between the columns and between columns and reservoirs gives a set of equations that, with some simplifying assumptions, may be solved. In figure 6 , we compare the calculated initial mass transport of a combination of $n$ columns to 1 with that obtained if we take the same number of columns combined 1 to 1 . For $\mathrm{n}<6$ the combination $\mathrm{n}$ to $\mathrm{l}$ is more efficient than 1 to 1 . The best result, an increase in TD transport with about 15 percent, is obtained for 3 to 1 .

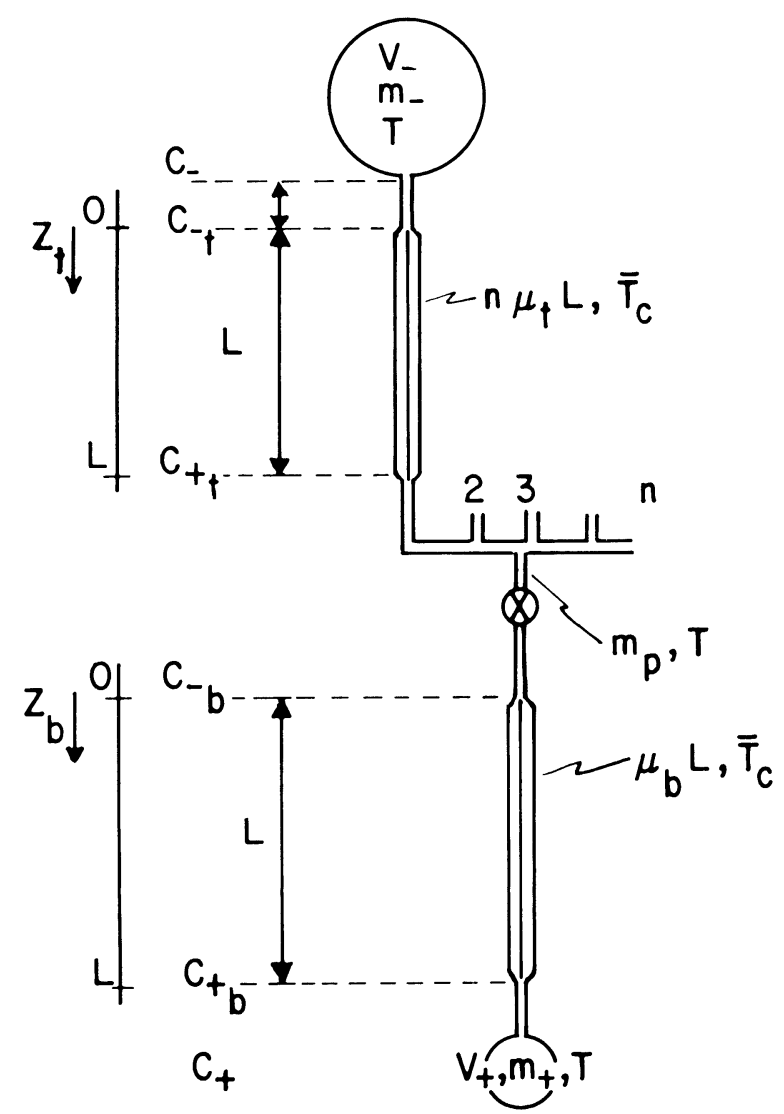

Fig. 5. Enrichment system of $\mathbf{n}$ parallel top columns, each of effective length $\mathbf{L}$ and with its own storage reservoir $V_{-.}$, in series with a single bottom column of the same length. $\mathrm{V}_{+}$- enrichment reservoir; $\mathrm{m}_{+}, \mathrm{m}_{-}, \mathrm{m}_{\mathrm{p}}-$ mass of gas in $\mathrm{V}_{+}$and $\mathrm{V}_{-}$and parasitic mass in connecting tubes, respectively; $\mathrm{n} \mu_{\mathrm{t}} \mathrm{L}, \mu_{\mathrm{b}} \mathrm{L}$-mass in the $\mathrm{n}$ top columns and in the bottom column resp., where $\mu$ is the mass per $\mathrm{cm}$ in the columns; $T, \bar{T}_{\mathrm{c}}-$ room temperature and average temperature of the gas in the columns; $\mathbf{C}_{-}, \mathbf{C}_{-}, \mathbf{C}_{+t}-$ concentration of the heavy isotope in $\mathrm{V}_{-}$, at the top and bottom of the top section; $\mathrm{C}_{-\mathrm{b}}$, $\mathrm{C}_{+\mathrm{b}}, \mathrm{C}_{+}$-concentration of the heavy isotope at the top and bottom of the column and in $\mathrm{V}_{+}$. 


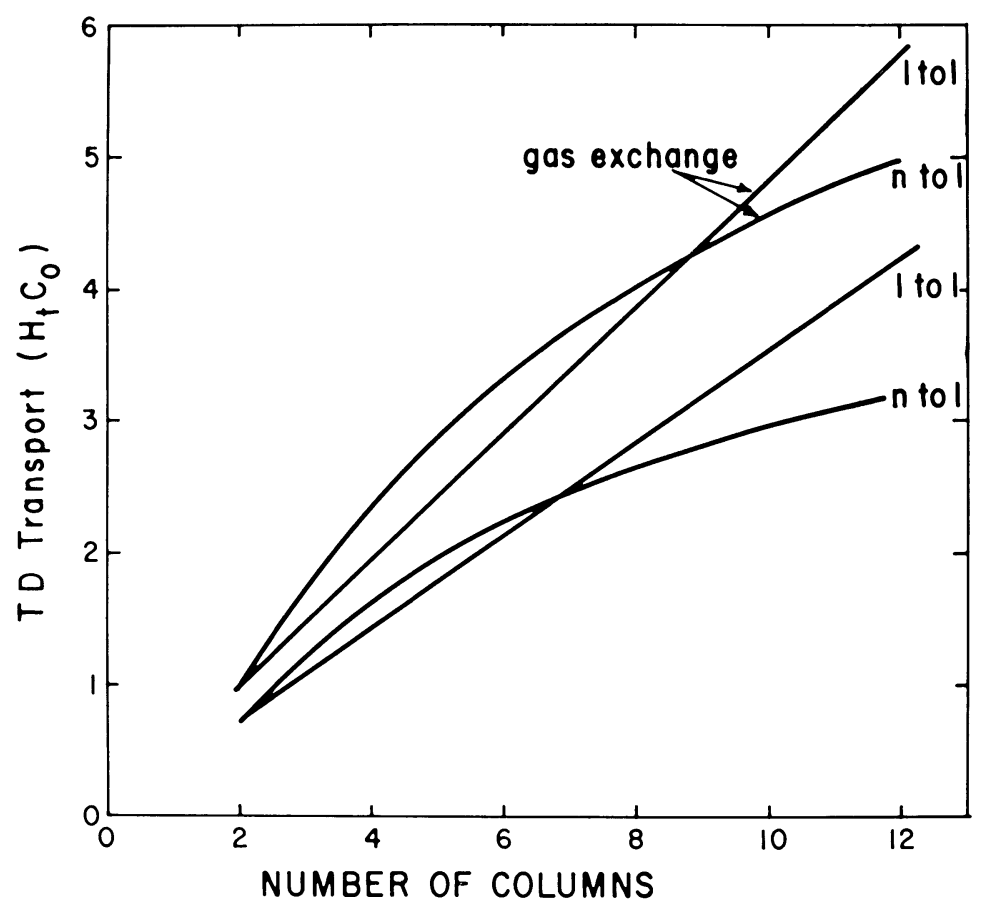

Fig. 6. Thermal diffusion transport in units $H_{t} C_{o}$ for $n+1$ columns combined 1 to $\mathbf{l}$ in series and combined $n$ parallel with 1 in series if no concentration diffusion gradients are present (gas exchange) and if concentration diffusion does exist (no gas exchange). The indices $t$ and $o$ refer to top column and the original concentration, respectively.

If we eliminate the necessity of concentration diffusion transport by forced gas exchange between the bottom of the top section and the top of the bottom column, and between $\mathrm{V}_{-}$and the top of the top section and $\mathrm{V}_{+}$and the bottom of the bottom column, we can considerably improve the TD transport of the system (fig 6, gas exchange). For this situation $\mathrm{n}$ $\leqslant 7$ is more efficient and the best result, about 22 percent gain, is obtained for 3 to 1 . The UW system consisting of 3 units of 4 to 1 and 2 of 3 to 1 (fig. 1) therefore has near optimum geometry.

\section{The equilibrium enrichment}

The equilibrium enrichment $q_{e}^{\prime}$ is found from $q_{e}$ and a mass balance of the system. Figure 7 shows $\mathrm{q}_{\mathrm{e}}$ and $\mathrm{q}_{\mathrm{e}}^{\prime}$ calculated for a 4 to 1 system at 850 torr pressure as a function of the hot wire temperature $T_{2}$ for 2 different cold wall temperatures. The mass ratio $\mathrm{m}_{\mathrm{t}} / \mathrm{m}_{+}(=16.9$ for this system) obviously is the main factor determining $q_{e}^{\prime}$ in this case. A positive effect of a dominance of $\mathrm{m}_{\mathrm{t}} / \mathrm{m}_{+}$is the attenuation of the effect of variations in hot and cold wall temperature. Their relative effect on $q_{e}^{\prime}$ is 10 to 20 times less than on $\mathrm{q}_{\mathrm{e}}$. Thus, the fluctuations in the cooling water temperature (cold wall temperature range $25-45^{\circ} \mathrm{C}$ ) will only produce 


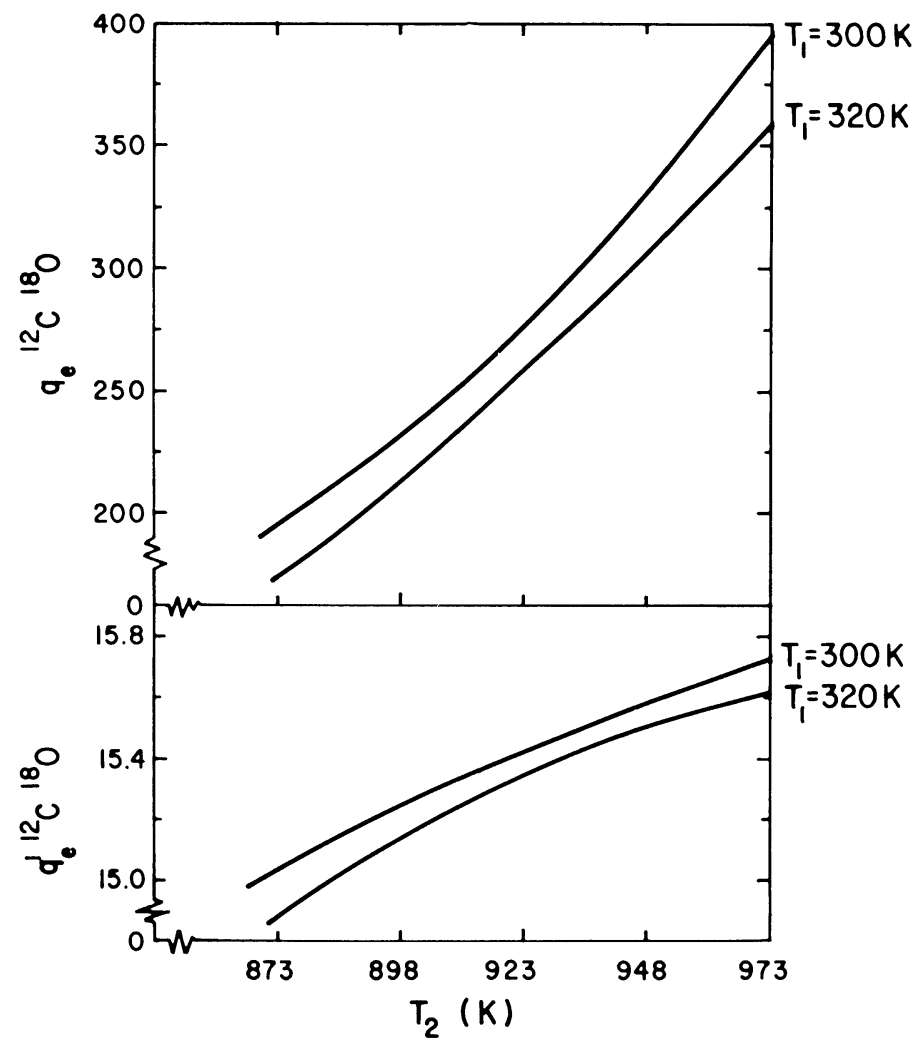

Fig. 7. The equilibrium separation factor $\mathrm{q}_{\mathrm{e}}$ and the equilibrium enrichment $\mathrm{q}_{\mathrm{e}}{ }^{\prime}$ as a function of wire temperature $\mathrm{T}_{2}$ for ${ }^{12} \mathrm{C}^{18} \mathrm{O}$ in a 4 to 1 system $\left(\mathrm{r}_{1 \text { top }}=0.5 \mathrm{~cm}\right.$, $\mathrm{r}_{\text {1bot tom }}=0.45 \mathrm{~cm}$ ) at 850 torr and $\mathrm{T}_{1}=300$ and $320 \mathrm{~K}$.

variations in $\mathrm{q}_{\mathrm{e}}^{\prime}$ of 0.5 to $1 \%$. The enrichment of the system is therefore rather reproducible and stable. The change in calculated equilibrium enrichment $\mathrm{q}_{\mathrm{e}}^{\prime}$ with the mass ratio $\mathrm{m}_{\mathrm{t}} / \mathrm{m}_{+}$is shown in figure 8 for a 4 to 1 system with $\mathrm{q}_{\mathrm{e}}=276$. The different mass ratios of the UW system (a) and that routinely used in Groningen (b) may be the main reason for the difference in enrichments. When $\mathrm{q}_{\mathrm{e}}>10 \mathrm{~m}_{\mathrm{t}} / \mathrm{m}_{+}$the difference between $\mathrm{q}_{\mathrm{e}}^{\prime}$ and $\mathrm{m}_{\mathrm{t}} / \mathrm{m}_{+}$is $<13 \%$ and $\mathrm{q}_{\mathrm{e}}^{\prime}$ increases linearly with $\mathrm{m}_{\mathrm{t}} / \mathrm{m}_{+}$. Only when $\mathrm{q}_{\mathrm{e}}<10 \mathrm{~m}_{\mathrm{t}} / \mathrm{m}_{+}$(small $\mathrm{q}_{\mathrm{e}}$, large $\mathrm{m}_{\mathrm{t}} / \mathrm{m}_{+}$) this linear relation breaks down. In practice, the equilibrium enrichment is never reached because, in the final stage, the increase of enrichment with time is very slow. Therefore the transport and enrichment of the system in the initial and the transient phase are of practical interest.

\section{The initial phase}

The initial phase lasts only as long as no significant depletion or concentration build-up occurs. Since quasi-stationary transport in our system requires considerably different concentrations in different parts of the 


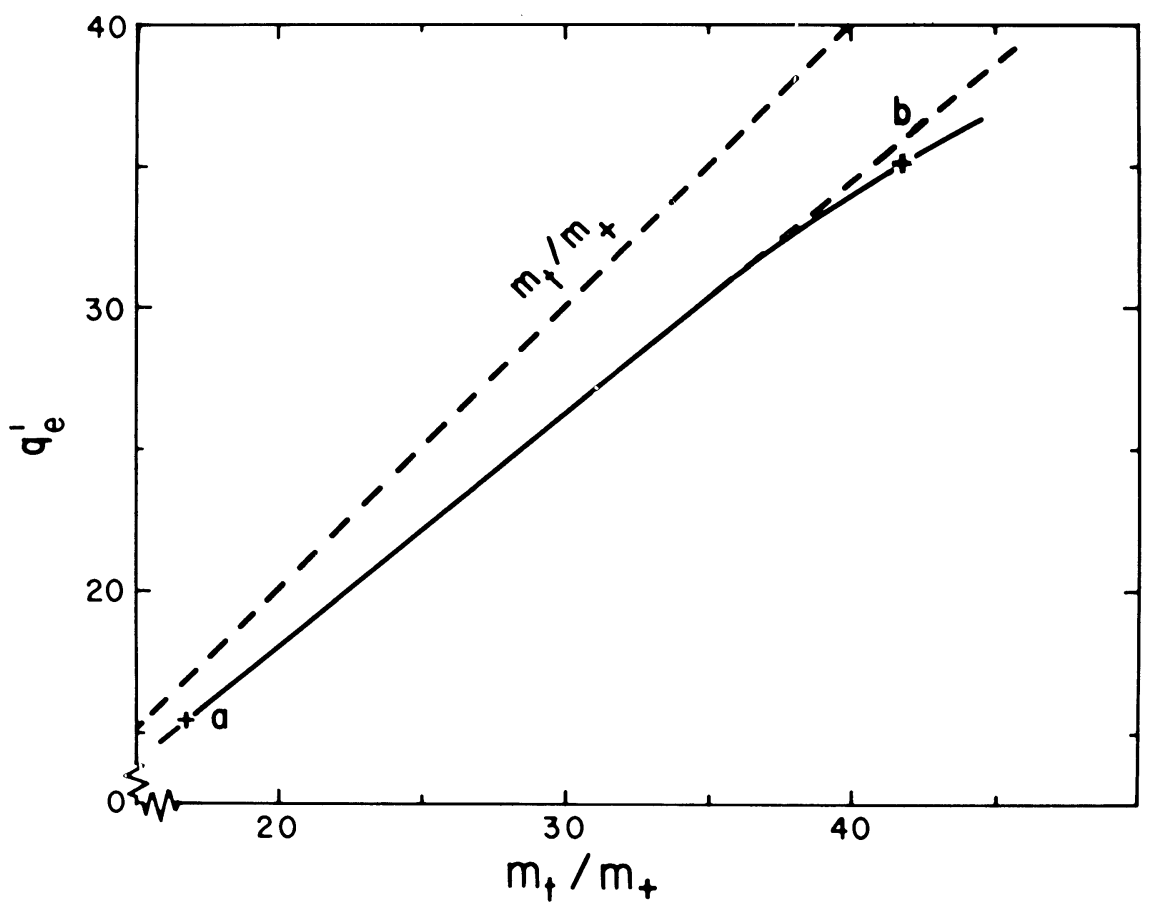

Fig. 8. Relation between the equilibrium enrichment factor $\mathrm{q}_{\mathrm{e}}^{\prime}$ and the ratio total sample mass $/$ mass of the enriched sample, $\mathrm{m}_{t} / \mathrm{m}_{+}$, for a 4 to 1 system with $\mathrm{q}_{\mathrm{e}}=276$. a-the UW system, b-the routine value of the Groningen system.

system (even with gas exchange), this phase will last for a very short time, probably less than a day. For 7 enrichments under varying conditions, we measured the enrichment as a function of time by taking small samples of the gas in $\mathrm{V}_{+}$.

The first was at lower wire temperature $(\approx 860 \mathrm{~K})$ without gas exchange as was routine before July 1977. The second was a trial in which 2 systems were subjected to forced gas exchange between top and bottom columns and between columns and reservoirs and 2 were heated to a higher temperature $(\approx 960 \mathrm{~K})$. The other 5 combined the high temperature with different gas exchange frequencies. Gas exchange was effected by a gas swing, heating the top reservoirs $\mathrm{V}_{-}$with heating tape for about 30 min, which caused a pressure increase of about 50 torr, and cooling for another $30 \mathrm{~min}$. The amount of gas forced out of $\mathrm{V}_{-}$is a little more than that needed to replace the gas in the connecting tubes.

The TD transport coefficient $\mathrm{H}$ can be found from the initial enrichment. From eq 1, it follows, for a single column, that in the initial phase, before concentration gradients have been built up, $\tau=$ HC. Measuring the increase in concentration as a function of time enables us to calculate the transport, $\tau$. From this transport during the first few days of the en- 
richment, and the isotopic composition of the gas $(\mathrm{C})$, we obtain an experimental measure of the $\mathrm{TD}$ transport coefficient of the system. In a composite system like ours transport is not only determined by the columns, but also by their combination. The calculation, therefore, yields an effective system transport coefficient $H_{s}$. The observed $H_{s}$ is a minimum value for the system TD transport coefficient, because we can only determine it from the build-up of a concentration gradient in the system. Nevertheless, it allows an estimate of the agreement between the calculated TD transport coefficient of the columns and reality.

To get sufficient measurements the results of the first 4 days were used to determine the initial transport. We calculated $\mathrm{H}_{\mathrm{s}}$ from

$$
\mathrm{H}_{\mathrm{s}}=\frac{\mathrm{M}_{2}}{\mathrm{M}_{1}} \mathrm{~m}_{+}{ }^{\prime} \frac{\mathrm{dq}^{\prime}}{\mathrm{dt}} \text {. }
$$

Here $M_{2}$ and $M_{1}$ are the molecular weight of the heavy and the light isotopic species, respectively and $\mathrm{m}^{\prime}{ }_{+}$is the mass in the enrichment reservoir plus that in the lower column. The factor $\mathrm{M}_{2} / \mathrm{M}_{1}$ is necessary because $\mathrm{H}_{s}$ gives the mass transport of the heavy isotopic species, while $\mathrm{m}_{+}{ }_{+}$is based on the actual gas, mainly the light isotope. The use of $\mathrm{m}^{\prime}+$ instead of $m_{+}$reflects the considerable concentration build-up in the bottom column during the first phase of the enrichment necessary to obtain a constant transport through the system. The experimental system TD transport coefficients $H_{s}$ were divided by the number of columns of the system (4 or 5 ) to get a measure of the net separating mass transport obtained per unit investment (column, power, cooling water) (table 2). This also provides a basis for comparison with the Groningen system.

From table 2 it seems that increasing the wire temperature from 860 $\mathrm{K}$ to $960 \mathrm{~K}$ (average gain 24 percent) was less important than reducing the concentration diffusion gradients by gas exchange (average gain 57 percent). The observed overall increase in initial transport of about 80 percent is considerable and results in a much faster approach to the equilibrium enrichment.

To compare the observed system TD transport with theory, we first calculated the TD transport coefficients $H$ for the different experiments from the gas properties, system parameters, and the experimental TD coefficient $\alpha$ (Boersma-Klein and de Vries, 1966) using the Lennard-Jones 12-6 potential model. From $\mathrm{H}$ we calculated system TD transport coefficients $H_{s}$ taking into account the reduction in transport caused by the gradients of concentration diffusion in connecting tubes and/or by the higher concentration at the top of the bottom column required by the $\mathbf{n}$ to 1 system geometry (calculation to be published elsewhere). Dividing $\mathrm{H}_{\mathrm{s}}$ by the number of columns in the system allows a comparison with our experimental results (table 2). Observed transports are only 50 to 60 percent of those calculated. The calculated reduction of the initial system mass transport due to concentration gradients depends on both $\mathrm{H}$ and $\mathrm{K}$. The presence of parasitic mixing $\left(\mathrm{K}_{\mathrm{p}}\right.$, not considered in the calculation) and of factors reducing $\mathrm{H}$ and/or increasing $\mathrm{K}$ will, therefore, lead to an 
observed mass transport that is lower than calculated. Also the use of measurements over the first 4 days yields a minimum value for the initial transport and may account for part of the observed discrepancy. The agreement between calculated and observed gain is excellent.

The calculated mass transports for the 5 systems at $960 \mathrm{~K}$, with gas exchange, are rather similar. We can, therefore, use the observed transports in table 2 to compare the relative system performances. The difference in transport between supposedly identical systems is of the order of 20 percent for \#1 and \#5. The difference between \#1 and the three 4 to 1 systems is approximately 10 percent and equals one standard deviation. This means that these 4 systems are not significantly different. Only \#5 is less efficient. The difference of 20 percent is of the same order as the maximum difference observed between the single 1 to 1 columns in Groningen (Grootes et al, 1975) and apparently indicates the variation encountered in the construction of "identical" hot-wire column systems. The initial TD transport of Groningen column 1 (performance close to the average of all 9 columns) gives $1.79 \times 10^{-6} \mathrm{~g} / \mathrm{sec} /$ column or 16 percent less than the average value of $2.13 \times 10^{-6}$ for the $5 \mathrm{UW}$ systems. The Groningen system was not subjected to gas exchange and operated at $\approx 920 \mathrm{~K}$. Since a calculation indicates that the concentration diffusion gradients reduce the initial transport by about 20 percent, we may conclude that the physical properties of the UW and the Groningen systems are very similar as far as the initial transport is concerned.

TABLE 2

Initial mass transport for the UW systems under different operating conditions

\begin{tabular}{|c|c|c|c|c|c|}
\hline & & & ransport mass & $\left(10^{-6} \mathrm{~g} / \mathrm{sec} /\right.$ & n) \\
\hline & & $\begin{array}{c}\text { Original } \\
\mathrm{T}_{2}=860 \mathrm{~K}\end{array}$ & $\begin{array}{c}\text { Gas exchange } \\
\mathrm{T}_{2}=860 \mathrm{~K}\end{array}$ & $\mathrm{~T}_{2}=960 \mathrm{~K}$ & $\begin{array}{c}\text { Gas exchange } \\
\mathrm{T}_{2}=960 \mathrm{~K}\end{array}$ \\
\hline \#1 & Observed & 1.54 & 2.02 & & $2.39 \pm 0.16^{\mathrm{a}}$ \\
\hline & Calculated & 2.18 & 3.28 & & 3.99 \\
\hline$\# 2$ & Observed & & & & $2.13 \pm 0.21$ \\
\hline & Calculated & & & & 3.98 \\
\hline$\# 3$ & Observed & & 1.46 & & $2.06 \pm 0.13$ \\
\hline & Calculated & & 3.16 & & 3.92 \\
\hline$\# 4$ & Observed & 1.04 & & 1.17 & $2.13 \pm 0.14$ \\
\hline & Calculated & 2.08 & & 2.55 & 3.93 \\
\hline$\# 5$ & Observed & & & 1.24 & $1.94 \pm 0.12$ \\
\hline & Calculated & & & 2.62 & 4.03 \\
\hline Avera & & Observed & $57 \%$ & $24 \%$ & $80 \%$ \\
\hline gair & & Calculated & $53 \%$ & $23 \%$ & $86 \%$ \\
\hline
\end{tabular}

a uncertainty in mean, based on observed scatter of measurements from different experiments; variability of transport due to small changes in TD parameters like column temperature and filling pressure is large, this contributes to overall uncertainty given; within each single experiment the difference between the different systems is present with a smaller standard deviation. 


\section{The transient phase}

In figure $9 \mathrm{~A}, \mathrm{~B}$, we give the enrichment in system 1 and 4 , respectively, as a function of time for 5 enrichments. When we compare the enrichment under the original conditions $\left(\bullet: \mathrm{T}_{2}=860 \mathrm{~K}\right.$, no gas exchange) with the others, we see that the main improvement of the new conditions is a faster approach to equilibrium. Between 10 and 30 days the enrichment is significantly higher than before, but after 40 to 50 days the change is small. The results for the enrichment during which gas exchange was increased (x: coal-9, 19 min heating/cooling, pressure difference $\approx 60$ torr) are similar to the other enrichments with gas exchange during the first 2 weeks but then fall below the others. After about 4 weeks equilibrium seems to have been reached at a value of $q^{\prime}$ about 15 percent $(\# 1)$ and $\approx 30$ percent $(\# 4)$ below that of the other enrichments. This indicates that forced gas exchange is not just beneficial in that it reduces concentration diffusion gradients and thus enhances TD transport, but that it probably also results in some mixing in the columns and disturbance of the concentration gradient built up in the columns by TD. For this reason, we henceforth stopped the forced gas exchange after $\approx 17$ days. By that time, TD transport decreased considerably due to depletion of $\mathrm{V}_{-}$and the build-up of a concentration gradient over the column so the disturbing influence becomes more important than the gain due to the reduction of concentration diffusion.

Although the 3 other enrichments shown in figure $9 \mathrm{~A}, \mathrm{~B}$ were all under somewhat different conditions, the difference in enrichment at a certain time generally is of the order of 10 percent or less. The enrichment systems seem to work rather reproducibly. The attenuation of the influence of variation of parameters like hot and cold wall temperature and pressure by the constant ratio $\mathrm{m}_{\mathrm{t}} / \mathrm{m}_{+}$probably is an important factor in this system reproducibility. It enables us to predict with reasonable accuracy the enrichment obtained after a certain time and thus to choose an enrichment time according to our needs.

The enrichment during the transient phase was calculated using an approximation described by Felber and Pak (1974) in which enrichment and depletion of the gas in the columns are accounted for by adding a correction term to the mass of the gas in the enrichment reservoir, while the columns are treated as having a volume zero. This way the enrichment $\mathrm{q}^{\prime}$ as a function of time $\mathrm{t}$ can be approximated by a simple exponential:

$$
\mathrm{q}^{\prime}(\mathrm{t})=\mathrm{q}_{\mathrm{e}}^{\prime}-\left(\mathrm{q}_{\mathrm{e}}^{\prime}-1\right) \exp \left(-\mathrm{t} / \mathrm{t}_{\mathrm{r}}\right)
$$

where $q_{e}{ }^{\prime}$ is the final equilibrium value of $q^{\prime}$ and $t_{r}$ is the time in which $\mathrm{q}_{\mathrm{e}}^{\prime}$ would be reached if the initial transport continued. To give a realistic description of the enrichment system the constraints on the mass transport, due to the connection of 3 or 4 columns to 1 and to the concentration diffusion mass transport through connecting tubes, have to be considered. Using eq 4, we calculated the increase in enrichment during consecutive short time intervals for quasi-stationary transport with these con- 


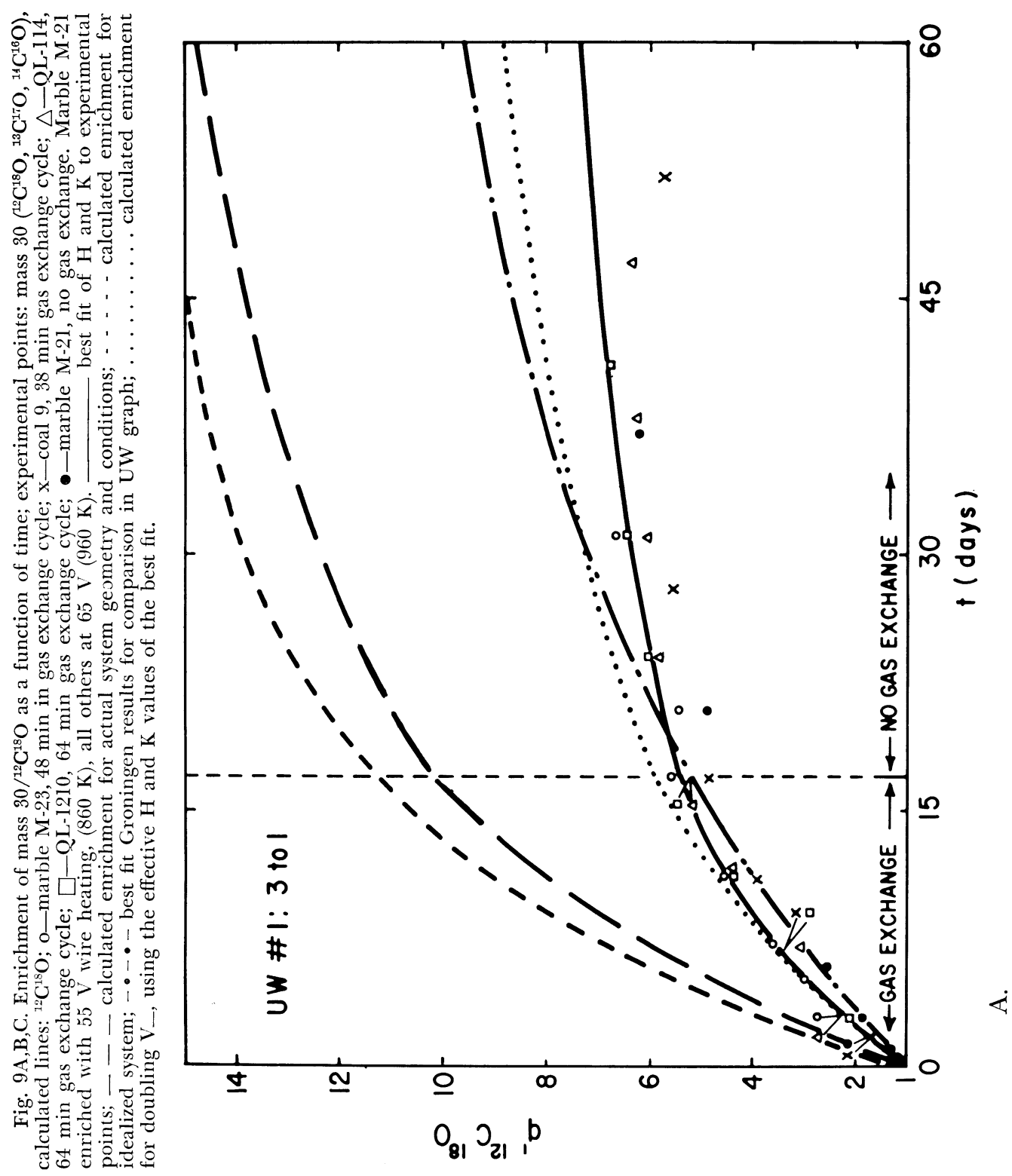




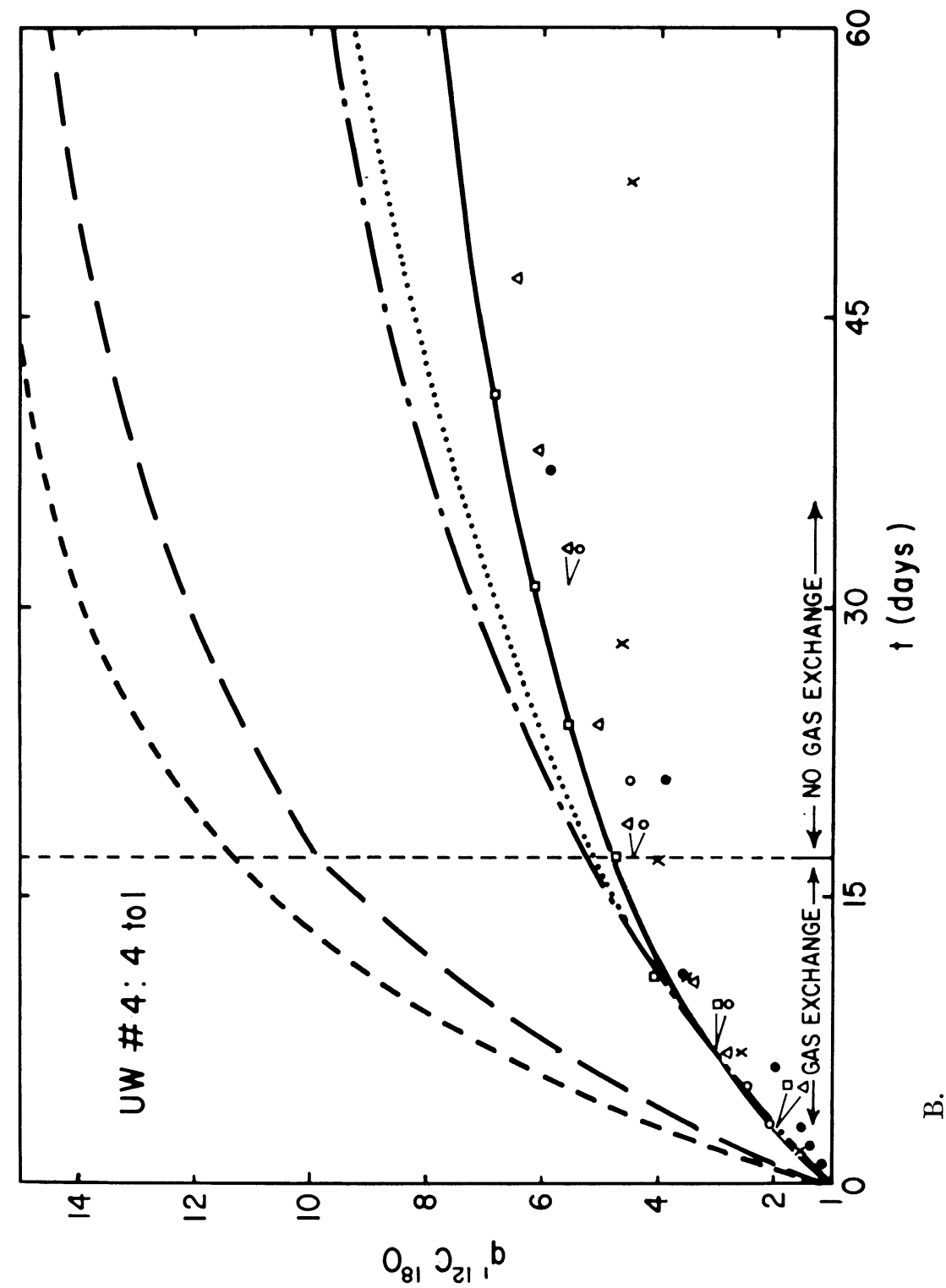




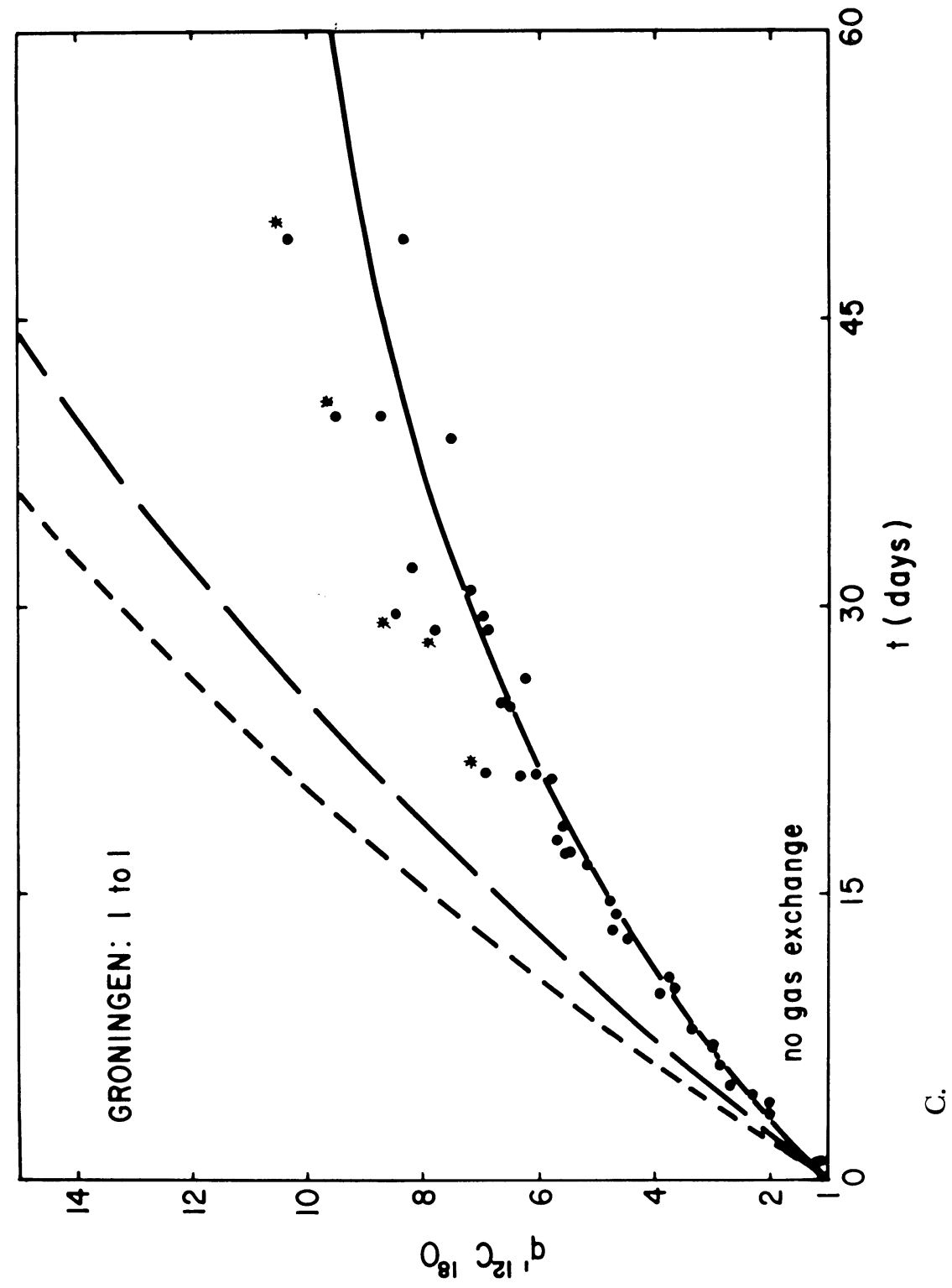


straints and the initial and the theoretical equilibrium state as boundary conditions (fig 9A,B). The calculations will be described elsewhere.

Because gas exchange is stopped after 17 days, the predicted enrichment curve is that for a sample with ideal gas exchange for the first 17 days and, after that, for a system without gas exchange continuing from the enrichment built up in those first 17 days. Comparison of the increase in enrichment when the enrichment system geometry is considered in detail, with that of an "idealized" system, shows that the more accurate description predicts 10 to 20 percent lower enrichments in the transient phase. Observed enrichments, however, are still considerably lower (by as much as 50 percent). To evaluate this difference in terms of our transport coefficients $\mathrm{H}$ and $\mathrm{K}\left(=\mathrm{K}_{\mathrm{c}}+\mathrm{K}_{\mathrm{d}}\left(+\mathrm{K}_{\mathrm{p}}\right)\right)$, where $\mathrm{K}_{\mathrm{p}}$ represents parasitic mixing, we varied the values of $\mathrm{H}$ and $\mathrm{K}$ used in our calculation till a satisfactory fit to experimental results was obtained. Because the enrichments in figure $9 \mathrm{~A}, \mathrm{~B}$ were all under slightly different conditions, we chose one, $\square$ : QL -1210 , to make our fit. This run gave the best enrichment and was considered most representative of present system operation. Because the gas exchange probably also introduces some parasitic mixing in the columns, which would be apparent as a larger $\mathrm{K}_{\mathrm{p}}$, we made separate fits for the first 17 days and the remaining enrichment, keeping $\mathrm{H}$ constant. The results are given in table 3.

An independent estimate of both $\mathrm{H}$ and $\mathrm{K}$ is obtained, because initially the enrichment is mainly determined by $\mathrm{H}$; but near equilibrium by $\mathrm{H}$ and $\mathrm{K}$ combined. The value of $0.8 \mathrm{H}$ (plus or minus a few percent) giving the best fit in both geometries combined with the larger $\mathrm{K}$ would lower the calculated initial mass transports in table 2 by about 40 percent. The observed values, then, are about 90 percent of those calculated. Since over the first 4 days not the true initial transport, but rather the first part of the transient phase was sampled, a lower experimental $\mathrm{H}$ can be expected. The lower $\mathrm{K}$, when gas exchange stops, gives a quantitative indication of the disturbance and parasitic mixing introduced by gas exchange. For the 4 to 1 system considered it is apparently more serious than for the 3 to 1 . The values of $H$ and $\mathrm{K}$ are very sensitive to the cold wall temperature $T_{1}$ and to the column radius $r_{1}$. Since $H, K_{c}$ and $K_{d}$ are influenced by these parameters in the same direction, however, they cannot explain

TABLE 3

Effective transport coefficients deduced from experimental enrichment results

\begin{tabular}{|c|c|c|c|}
\hline System & Condition & $\mathbf{H}_{\text {eff }} / \mathbf{H}_{\text {theory }}$ & $\mathrm{K}_{\text {ert }} / \mathrm{K}_{\text {theory }}$ \\
\hline$\# 1$ & Gas exchange, $\mathrm{t}<17$ days & 0.8 & 1.85 \\
\hline 3 to 1 & No gas exchange, $\mathrm{t}>17$ days & 0.8 & 1.75 \\
\hline$\# 4$ & Gas exchange, $\mathrm{t}<17$ days & 0.8 & 2.0 \\
\hline 4 to 1 & No gas exchange, $\mathrm{t}>17$ days & 0.8 & 1.6 \\
\hline Groningen & No gas exchange & 0.95 & 2.0 \\
\hline
\end{tabular}


both the observed discrepancies. A value for the TD constant $\alpha$ (in $\mathrm{H}$ ) that is 20 percent too high and a very large $\mathrm{K}_{\mathrm{p}}\left(0.6\right.$ to $\left.0.7\left(\mathrm{~K}_{\mathrm{c}}+\mathrm{K}_{\mathrm{d}}\right)\right)$ act independently and would explain the observations. Variations in $r_{1}$ and $\mathrm{T}_{1}$ along the column (the latter due to the temperature increase of the cooling water during its contact with the column) affecting $\mathrm{H}$ and $\mathrm{K}$ differently may also account for part of the observed discrepancies.

In figure $9 \mathrm{C}, 5$ enrichments with the Groningen TD system are given (Grootes, 1977). Using the same calculating procedure as for $9 \mathrm{~A}, \mathrm{~B}$, a line was fitted to the points. These mostly resulted from samples taken from column \#1 for $\mathrm{V}_{-}=201 \mathrm{~L}(3 \times)$ and $\mathrm{V}_{-}=231 \mathrm{~L}(2 \times)$, but the compositions of the final, averaged enriched samples of all 9 columns are also given (*). The line gives an average performance of column \#1 for the 2 closely similar situations. If sampling disturbs the enrichment, this will provide the best comparison with the UW systems of figure $9 \mathrm{~A}, \mathrm{~B}$ which were likewise regularly sampled. It should be noted, however, that for these enrichments the average enrichment of the complete system is 10 to 15 percent higher than that of column \#1. For comparison the line fitted to the experimental points of the Groningen column \#1 is given in figure $9 \mathrm{~A}, \mathrm{~B}$.

The enrichment of the Groningen system is closely similar to that of UW system \#4 in figure 9B and somewhat lower than that of \#1 in figure 9A during the first 2 weeks. Since its rate of enrichment decreases less rapidly, the Groningen enrichment becomes larger than that of the UW systems after about 3 weeks. The effective values of $\mathrm{H}$ and $\mathrm{K}$ that fit the experimental results deviate from theory in a similar way as those of the UW systems (table 3), although they are relatively somewhat larger. This agrees with the similar results obtained for $\mathrm{H}$ in the initial phase. To evaluate the influence of sample size on the enrichment, we calculated the enrichment of the UW systems as a function of time for a doubling of the reservoir size $V_{-}$(fig $9 A, B$ ) and for a $V_{-}$giving the same $m_{t} / m_{+}$as in Groningen, using the effective values of $\mathrm{H}$ and $\mathrm{K}$ from table 3 . The same $\mathrm{m}_{\mathrm{t}} / \mathrm{m}_{+}$resulted in an enrichment curve (not shown) that closely approached that of the Groningen system after 4 to 5 weeks. This suggests that the two enrichment set-ups, although of different geometry, behave similarly not only in the initial but also in the transient phase and that the difference in observed enrichment is mainly caused by the different ratio $\mathrm{m}_{\mathrm{t}} / \mathrm{m}_{+}$. From figure $9 \mathrm{~A}, \mathrm{~B}$ we see that doubling $\mathrm{V}_{-}$will increase the enrichment by about 10 percent after 30 days and about 15 percent after 40 days. This corresponds to a gain in age range of 800 to 1100 years. Therefore, although some gain in age range can be obtained by increasing the sample size, efforts to reduce $\mathrm{K}$ may, for the moment, be more effective. Here it is important to note, that, although the UW systems have been constructed without spacers to center the wire, thus introducing possible parasitic convection mixing, their effective $\mathrm{K}$ values are somewhat lower than that of the Groningen system in which the wire is centered by triangular spacers. The cause of the high $\mathrm{K}$ values observed therefore deserves further attention. 
Figure 10 show the enrichment of all 5 UW systems during a typical enrichment under the new conditions, $i e, \mathrm{~T}_{2}=960 \mathrm{~K}$ and gas exchange during the first 17 days. The differences between the individual systems found for the initial transport (table 2) obviously persist through the transient phase. The enrichment can best be stopped after about 4 weeks, for after this time the increase in enrichment slows. In 4 weeks with the present system, a sample enriched by a factor $\approx 5.5$ in ${ }^{18} \mathrm{O}$ or about 7 in ${ }^{14} \mathrm{C}$ will be obtained giving a gain in age range of almost 16,000 years. The actual ${ }^{14} \mathrm{C}$ enrichment of a sample is calculated from the mass spectrometrically measured enrichment of mass 30 (mainly ${ }^{12} \mathrm{C}^{18} \mathrm{O}$ ) and an experimentally established relation between this enrichment and that of ${ }^{14} \mathrm{C}$. The uncertainty in the ${ }^{14} \mathrm{C}$ enrichment thus obtained is a few percent $(<5 \%)$. This is small compared with the statistical uncertainty in the ${ }^{14} \mathrm{C}$ activity of old samples and generally has a negligible influence on the uncertainty in the measured sample age.

\section{CONCLUSIONS}

(i) The combination of 3 or 4 columns in the top section to 1 column in the bottom section offers an advantage of about 20 percent for a system with gas exchange or 15 percent for a system without over a simple 1 to 1 system as far as initial thermal diffusion transport for a given energy consumption is concerned. This is the optimum value for the UW system.

(ii) The initial transport of the systems was increased by as much as 80 percent by increasing the hot wire temperature from 860 to $960 \mathrm{~K}$ $(\approx 24 \%)$ and by gas exchange $(\approx 57 \%)$.

(iii) The observed initial net thermal diffusion mass transport for mass 30 is of the order of $2.1 \times 10^{-6} \mathrm{~g} / \mathrm{sec} /$ column and 16 percent larger than in Groningen $\left(1.8 \times 10^{-6} \mathrm{~g} / \mathrm{sec} / \mathrm{column}\right)$. The difference is due to different operating conditions.

(iv) The mass ratio $m_{t} / m_{+}$is an important factor determining the enrichment provided $\mathrm{q}_{\mathrm{e}}>>\mathrm{m}_{\mathrm{t}} / \mathrm{m}_{+}$.

(v) The increase in initial transport due to gas exchange and temperature increase of the wire results in a faster approach to the equilibrium enrichment without substantially increasing this value.

(vi) The enrichment of the UW system in the transient phase is similar to that of the Groningen system. Differences are mainly attributable to the difference in $\mathrm{m}_{\mathrm{t}} / \mathrm{m}_{+}$.

(vii) The similarity in the enrichments of the UW and the Groningen systems suggests that hot wire column enrichment system geometry is not very critical, and that it is relatively easy to construct a system that works reproducibly and satisfactorily.

\section{ACKNOWLEDGMENTS}

Prior to 1975, S W Robinson assisted in testing and setting up the enrichment system for routine operation. I C Yang performed the enrichments from 1975 till early 1978. The results are reported in Stuiver, Heusser, and Yang (1978). During these enrichments the samples for the 


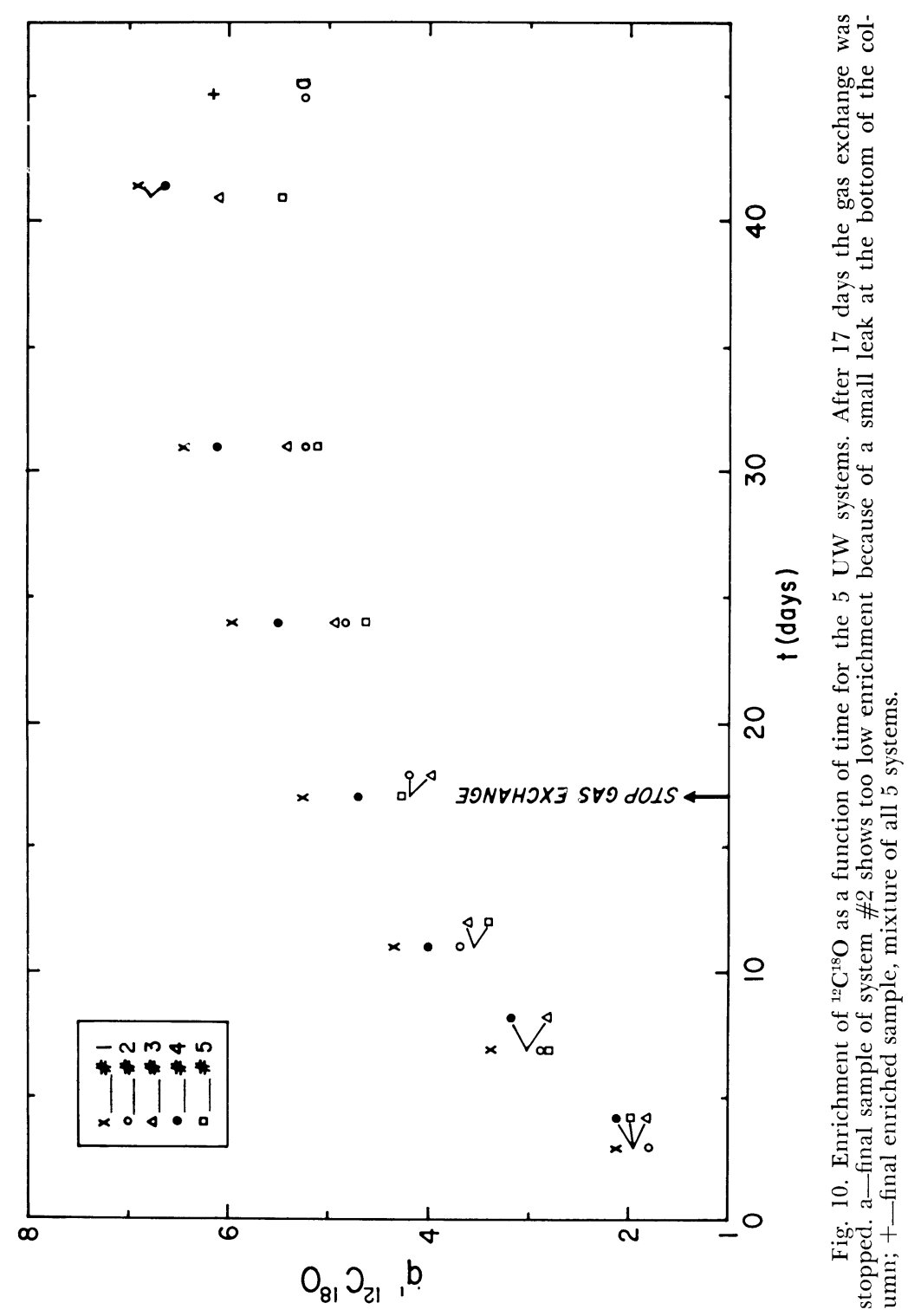


present study were taken. P J Wilkinson took care of sample pretreatment and combustion. The enrichment project was funded by N S F grant EAR 76-81598 Geochemistry Program. The critical comments of $\mathrm{H}$ Erlenkeuser (Kiel) substantially improved this paper.

\section{REFERENCES}

Agrawal, D P, Gupta, S K, and Kusumgar, Sheela, 1971, Tata Institute radiocarbon date list IX: Radiocarbon, v 13, p 442-449.

Bennett, C L, Beukens, R P, Clover, M R, Elmore, D, Gove, H E, Kilius, L R, Litherland, A E, and Purser, K H, 1978, Radiocarbon dating using electrostatic accelerators: dating of milligram samples: Science, v 201, p 345-347.

Bennett, C L, Beukens, R P, Clover, M R, Gove, H E, Liebert, R B, Litherland, A E, Purser, K H, and Sandheim, W E, 1977, Radiocarbon dating using electrostatic accelerators: negative ions provide the key: Science, v 198, p 508-510.

Boersma-Klein, $\mathrm{V}$ and Vries, A E, de, 1966, The influence of the distribution of atomic masses within the molecule on thermal diffusion. I. Isotopic $\mathrm{CO}$ and $\mathrm{N}_{2}$ molecules: Physica, v 32, p 717-733.

Buddemeier, R W, Young, A Y, Fairhall, A W, and Young, J A, 1970, Improved system of methane synthesis for radiocarbon dating: Rev Sci Instruments, v 41, p 652-654.

Erlenkeuser, H, 1971a, Aufbau einer Thermodiffusionsanlage zur Anreicherung von Methan-Isotopen im Hinblick auf die Verwendung bei Altersbestimmungen nach der ${ }^{14} \mathrm{C}$-Methode: Thesis, Kiel, Germany.

- 1971b, Predictable low enrichment of methane isotopes by Clusius-Dickel thermal-diffusion columns for use in radiocarbon dating technique: Zeitschr Naturforsch, v 26a, p 1365-1370.

A thermal diffusion plant for radiocarbon isotope enrichment from natural samples: internat conf, 9th, on radiocarbon dating, Proc, La Jolla, California (in press).

Felber, Hans and Pak, E, 1972, Erweiterung der ${ }^{14} \mathrm{C}$-Altersbestimmungsmethode durch quantitative Isotopenanreicherung im Trennrohr: Sitzungber Österr Akad Wiss, v 180, p 299-316.

1974, Quantitative isotope enrichment in a thermal diffusion arrangement: Appl Physics, v 5, p 147-152.

Grootes, P M, 1977, Thermal diffusion isotopic enrichment and radiocarbon dating beyond 50,000 years BP: Thesis, Univ Groningen, the Netherlands, $221 \mathrm{p}$.

1978, Carbon-14 time scale extended: comparison of chronologies: Science, v 200, p $11-15$

Grootes, P M, Mook, W G, Vogel, J C, Vries, A E de, Haring, A, and Kistemaker, J, 1975, Enrichment of radiocarbon for dating samples up to 75,000 years: Zeitschr Naturforsch, v 30a, p 1-14.

Haring, A, Vries, A E de, and Vries, Hl de, 1958, Radiocarbon dating up to 70,000 years by isotopic enrichment: Science, v 128, p 472-473.

Jones, R C and Furry, W H, 1946, The separation of isotopes by thermal diffusion: Rev Modern Physics, v 18, p 151-224.

Kretner, R, 1973, Quantitative Anreicherung von $\mathrm{C}^{14} \mathbf{H}_{4}$ mit dem Clusius-Dickelschen Trennrohr zur Anwendung in der ${ }^{14} \mathrm{C}$ Datierungsmethode: Thesis, Munich, Germany.

Kretner, $\mathrm{R}$ and Dickel, G, 1975, Enrichment of ${ }^{14} \mathrm{CH}_{4}$ by thermal diffusion for use in radiocarbon dating: Zeitschr Naturforsch, v 30a, p 554-560.

Malota, F, 1962, Eine Erweiterung der Methode für Altersbestimmungen durch Anreicherung des $\mathrm{C}^{14}$ Isotops im Trennrohr: Thesis, Munich, Germany.

Muller, R A, 1977, Radioisotope dating with a cyclotron: Science, v 196, p 489-494.

Muller, R A, Stephenson, E J, and Mast, T S, 1978, Radioisotope dating with an accelerator: a blind measurement: Science, v 201, p 347-348.

Nelson, D E, Korteling, R G, and Stott, W R, 1977, Carbon-14: direct detection at natural concentrations: Science, v 198, p 507-508.

Pak, E, 1970, Erweiterung der $\mathbf{C}^{14}$-Altersbestimmungsmethode durch Isotopenanreicherung im Trennrohr: Thesis, Vienna, Austria.

Rutherford, W M and Kaminski, K J, 1967, Experimental verification of the theory of the thermal-diffusion column: Chem Physics Jour, v 47, p 5427-5432. 
Stuiver, Minze, 1978, ${ }^{14} \mathrm{C}$ dating: a comparison of beta and ion counting: Science, v 202, p 881-883.

Stuiver, Minze, Heusser, C J, and Yang, I C, 1978, North American glacial history extended to 75,000 years ago: Science, v 200, p 16-21.

Stuiver, Minze, Robinson, S W, and Yang, I C, ${ }^{14} \mathrm{C}$ dating to 60,000 years BP with proportional counters: internat conf, 9th, on radiocarbon dating, Proc, La Jolla, California (in press).

Vasaru, G, Müller, G, Reinhold, G, and Fodor, T, 1969, The thermal diffusion column: Berlin, VEB Deutscher Verlag Wiss, $207 \mathrm{p}$.

Vogel, J C, and Waterbolk, H T, 1972, Groningen radiocarbon dates X: Radiocarbon, v 14, p 6-110.

Vogel, J C, and Zagwijn, W H, 1967, Groningen radiocarbon dates VI: Radiocarbon, v 9, p 63-106.

Vries, A E de, 1956, The enrichment of radioactive isotopes by thermal diffusion: Thesis, Univ Amsterdam, the Netherlands, $85 \mathrm{p}$.

Vries, Hl de and Barendsen, G W, 1953, Radiocarbon dating by a proportional counter filled with carbon dioxide: Physica, v 19, p 987. 